\title{
PERANCANGAN APLIKASI E-COMMERCE PADA TOKO LILI DENGAN PENERAPAN METODE WATERFALL
}

\author{
*Siti Aisyah, Rizky Amelia, Ika Sabrina, Titania Syahrifah \\ Program Studi Sistem Informasi Fakultas Teknologi dan Ilmu Komputer, Universitas Prima \\ IndonesiaSekip, Simpang Seikambing, Medan, Indonesia, 20111 \\ Email : *siti_aisyah@unprimdn.ac.id
}

\begin{abstract}
ABSTRAK- Perkembangan teknologi dan informasi saat ini membawa pengaruh yang cukup besar di hampir semua bidang, salah satunya di bidang penjualan. Maraknya persaingan bisnis menuntut bisnis untuk lebih kreatif dan inovatif dalam memasarkan produk mereka. Toko Lili Kosmetik yang merupakan salah satu toko yang memasarkan produk kecantikan. Selama ini penjualan dilakukan secara konvensional, sehingga hanya bisa menarik pelanggan di sekitar lokasi penjualan. E-commerce adalah teknologi informasi yang biasa digunakan untuk perdagangan. Dengan teknologi informasi seperti E-commerce diharapkan dapat meningkatkan penjualan dan menarik lebih banyak konsumen dari berbagai daerah. Desain E-commerce yang dilakukan dengan menggunakan model waterfall ini akan mampu menjawab permasalahan yang selama ini dialami di Toko Lili Kosmetik.
\end{abstract}

Kata Kunci : Waterfall, E-Commerce, Cosmetic, Sale, Website

\section{PENDAHULUAN}

Perkembangan teknologi saat ini mengalami pelonjakan yang besar. Internet salah satu teknologi yang dapat menghubungkan manusia dari berbagai penjuru[1]. Penggunaanya mulai dari tingkat nasional hingga internasional dan dari berbagai kalangan termasuk pihak industri perdagangan[2]. Selain digunakan untuk media komunikasi internet juga dimanfaatkan sebagai ajang jual-beli online yang juga disebut dengan $e$-commerce [3].

$E$ - commerce adalah suatu kegiatan perdagangan atau jual beli yang dilakukann di dunia maya[4]. Konsep jual beli online yang diterapkan membuat transaksi pembayaran juga dapat dilakukan secara online.

Toko Lili Kosmetik adalah usaha yang bergerak dalam bidang penjualan kosmetik dan alat make up. Kegiatan pemasaran dan proses penjualan pada Toko Lili Kosmetik masih manual dimana para pembeli harus datang langsung ke toko tersebut[5], pemasaran yang saat ini dilakukan dari mulut ke mulut. Mengingat tingginya persaingan saat ini dan kesulitan melakukan pergerakan beberapa aktivitas di tengah kondisi pandemi covid 19 maka pihak toko harus mampu mencari jalan untuk tetap mendirikan usaha yang digeluti. Dengan kemajuan teknologi yang ada saat ini diharapkan dapat memberikan keuntungan dan pangsa pasar yang lebih luas[6].

Agar kegiatan penjualan pada Toko Lili dapat terus berkembang, maka perlu adanya sebuah website yang dapat mendukung proses jual beli tersebut[7][8]. Penelitian ini dilakukan untuk merancang sebuah aplikasi jual beli secara online dapat memberikan kemudahan kepada pihak penjual maupun pembeli, dan proses transaksi tersebut dapat berjalan dengan lancar walaupun tidak dilakukan secara langsung atau tatap muka [9].

\section{METODE PENELITIAN}

\subsection{Kerangka Penelitian}

Kerangka penelitian yang diterapkan pada penelitian ini menggunakan model perancangan waterfall yang penerapannya secara sistematik dan sekuensial [10]. Adapun kerangka penelitian tersebut terdapat pada gambar 1 .

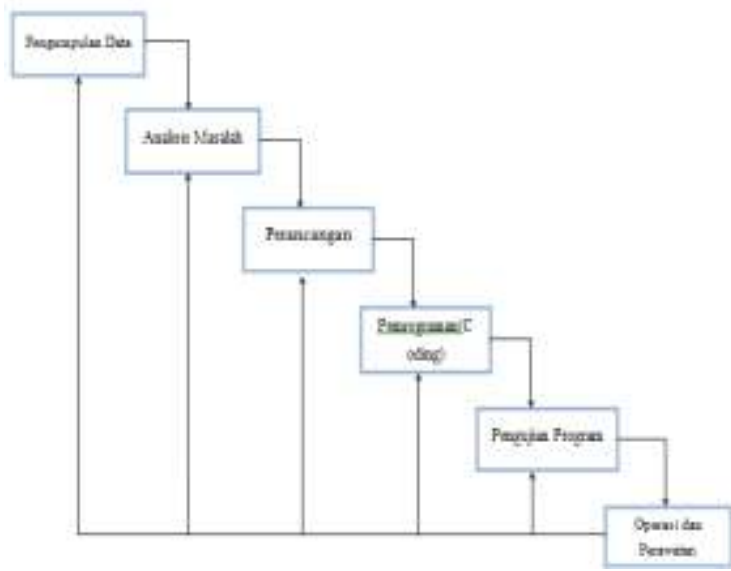

Gambar 1. Kerangka penelitian

1. Pengumpulan Data

Dalam penelitian ini, proses pengumpulan data yang dilakukan adalah dengan melaksanakan observasi langsung ke tempat riset yaitu Toko Lili Kosmetik.

2. Analisis Masalah

Setelah memperoleh data dan informasi langkah selanjutnya yang dilakukanada;ah analisis masalah. Hal ini dilakukan untuk mengevaluasi kecocokan data terhadap masalah yang ada. tersebut yang berkaitan dengan penginputan dan pengelolaan data. 


\section{Perancangan}

Setelah dilakukan tahap pengumpulan data dan analisis masalah, maka langkah yang selanjutnya yang dilakukan adalah melakukan perancangan yang dimana pada tahap ini merupakan tahap multilangkah yang terfokus pada pembuatan database, maupun desain interface.

4. Pemrograman

Dalam tahapan ini merupakan tahapan pembuatan program perangkat lunak sistem ecommerce termasuk struktur data dan prosedur pengcodingan.

5. Pengujian Program

Desain ini harus ditranslasikan kedalam perangkat lunak. Hasil dari tahap ini adalah program sesuai dengan desain yang telah dirancang. Pada tahap ini juga sebagai pengujian apakah semua unit sudah benar-benar teruji dengan benar.

6. Operasi dan Perawatan

Aplikasi yang sudah dirancang dan disampaikan ke pemesan akan mengalami perubahan. Perubahan tersebut dapat terjadi akibat kesalahan sistem maupun perubahan keinginan pelanggan.

\section{HASIL DAN PEMBAHASAN}

3.1 Analisis Kebutuhan Fungsional Kebutuhan fungsional dari sistem yang akan dibuat yaitu sebagai berikut:

a. Sistem harus dapat memberikan informasi tentang produk - produk fashion kepada konsumen dan masyarakat.

b. Kebutuhan dari sistem harus dapat menampilkan produk - produk make up, skin care dan produk terbaru lainnya.

c. Sistem harus dapat menangani proses pemesanan produk dengan mudah.

\subsection{Perancangan Sistem}

\section{Database}

Perancangan database utama dengan menggunakan Entity Relationship Diagram (ERD), disini menerjemahkan pemodelan data secara abstrak. Berikut rancangan ERD :

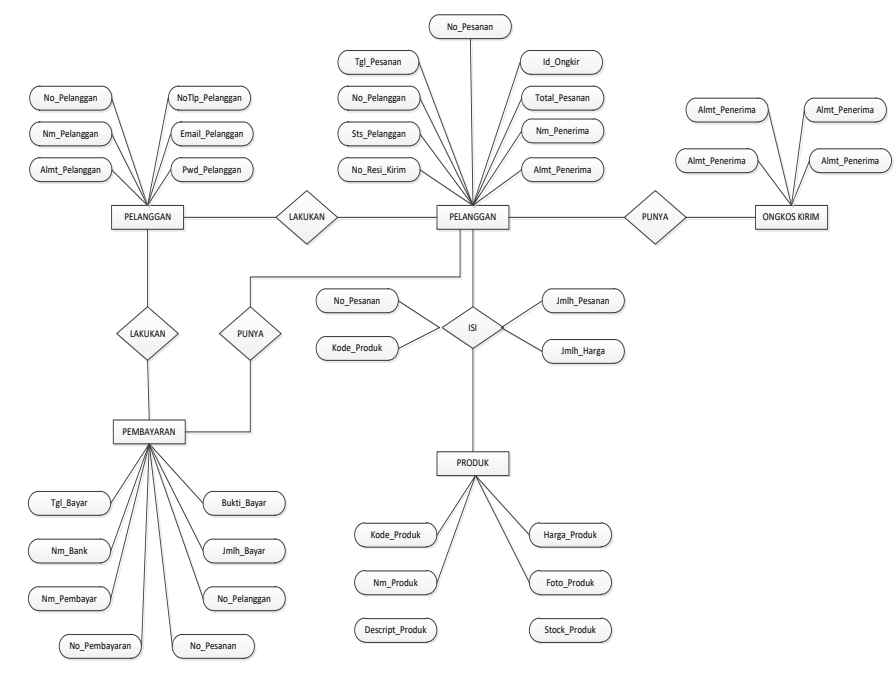

Gambar 2. Entity Relationship Diagram (ERD)

Berikut akan ditampilkan rancangan Logical Record Structure, dimana untuk menunjukkan

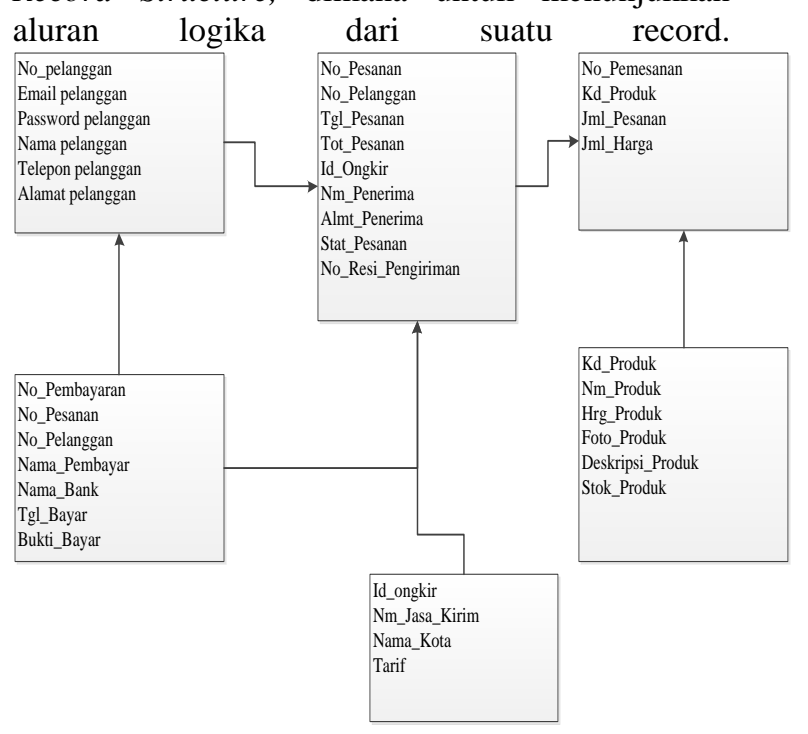

Gambar 3. Logical Record Structure Aplikasi Sistem Penjualan Kosmetik

\section{Perancangan Use Case}

Perancangan sistem yang dilakukan adalah pembuatan sistem informasi penjualan kosmetik berbasis web. Dimana perancangan sistem ini menggunakan rancangan use case diagram.

Use case dari sistem yang akan dikembangkan adalah sebagai berikut : 
JUSIKOM PRIMA (Jurnal Sistem Informasi dan Ilmu Komputer Prima)

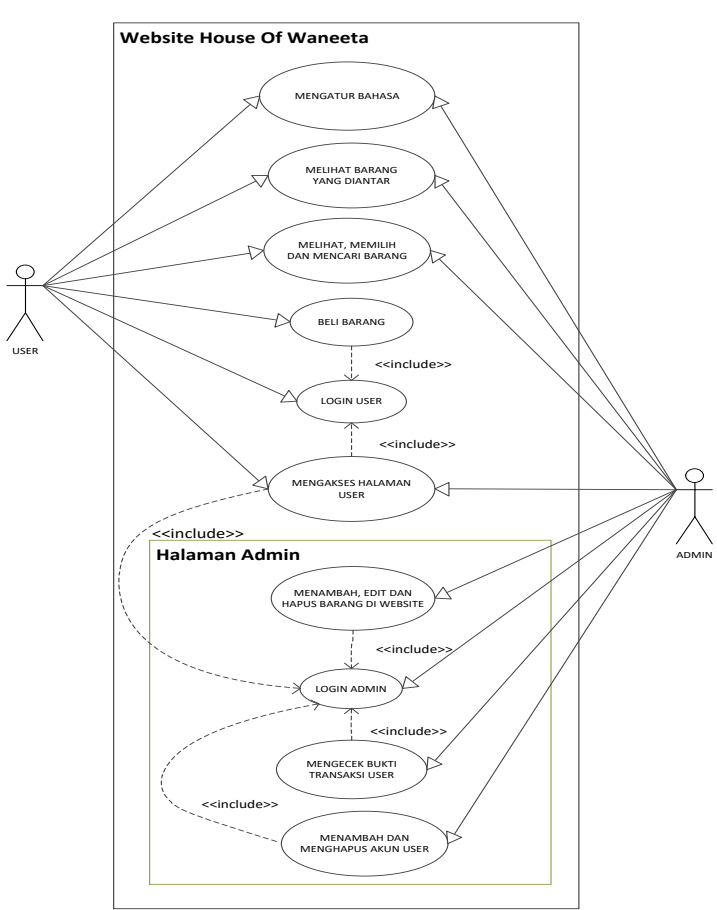

Gambar 4. Use Case Diagram

\subsection{Perancangan Navigasi Aplikasi Sistem} Penjualan Kosmetik

a. Navigasi Halaman User

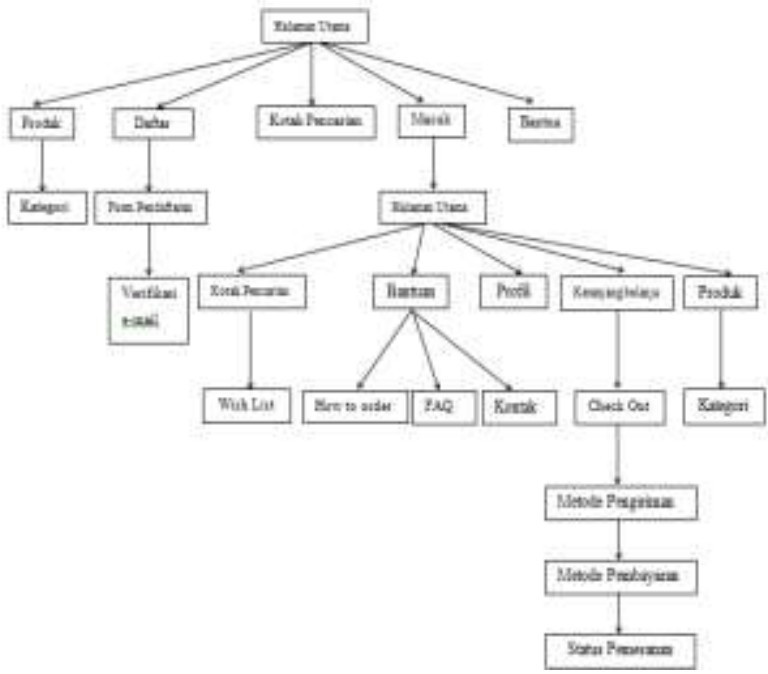

Gambar 4. Navigasi Halaman User b. Navigasi Halaman Bagian Admin

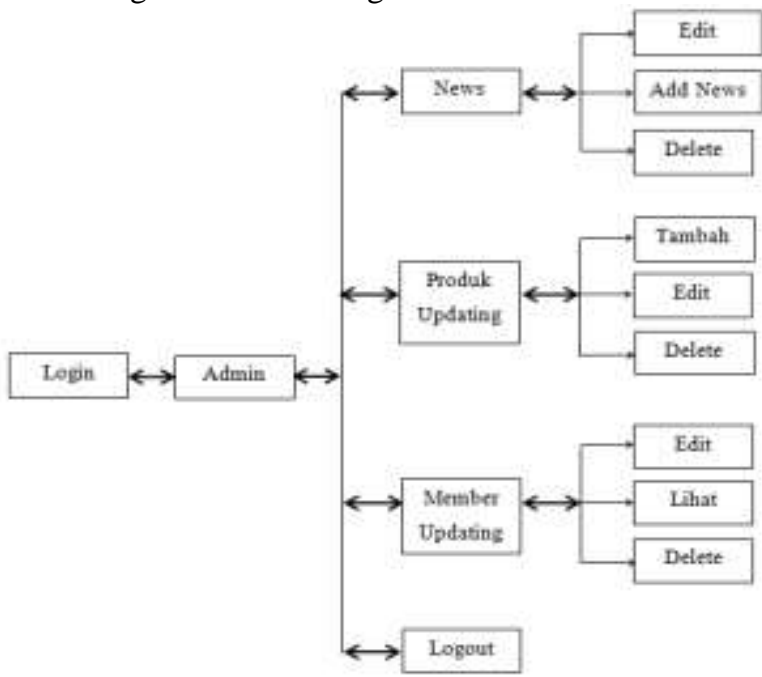

Gambar 5. Navigasi Halaman Bagian Admin

\subsection{Rancangan User Interface}

a. Halaman Dashboard

Menu ini adalah menu yang pertama setelah kita berhasil login. Halaman ini biasanya berisi shortcut dimana kita bisa melihat versi wordpress, theme yang digunakan, jumlah postingan, dan lain lain.

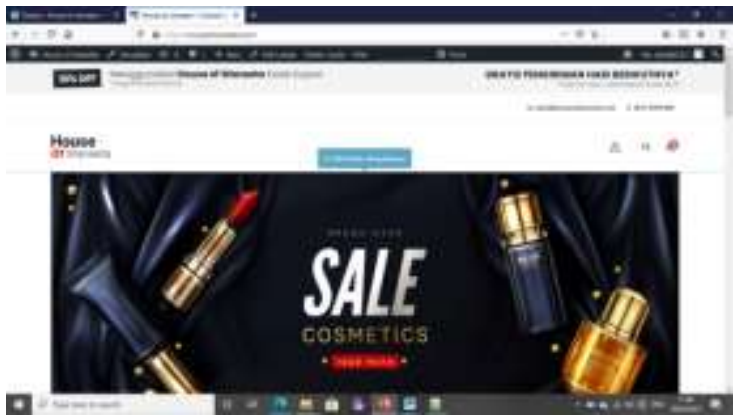

Gambar 6. Halaman Dashboard

b. Halaman Keranjang Belanja

Pada halaman berikut ini pelanggan dapat melihat barang yang sudah dimasukkan ke keranjang sebelumnya lalu klik checkout.

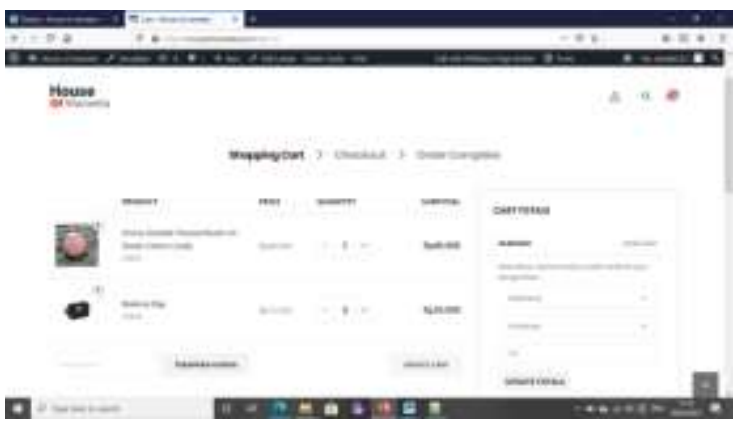

Gambar 7. Halaman Keranjang Belanja 
c. Halaman Checkout

Merupakan menu yang mengharuskan customer untuk melakukan registrasi sebelum melakukan proses check out.

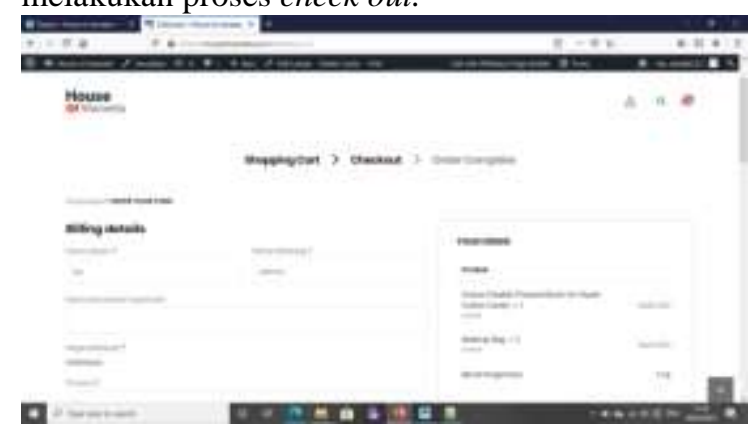

Gambar 8. Halaman Checkout

d. Halaman Metode Pembayaran

Ada beberapa metode pembayaran yang diberikan kepada pemesan. Metode yang diberikan itu diantaranya adalah melalui rekening yang nanti akan muncul nama dan nomor rekening si pemilik toko.

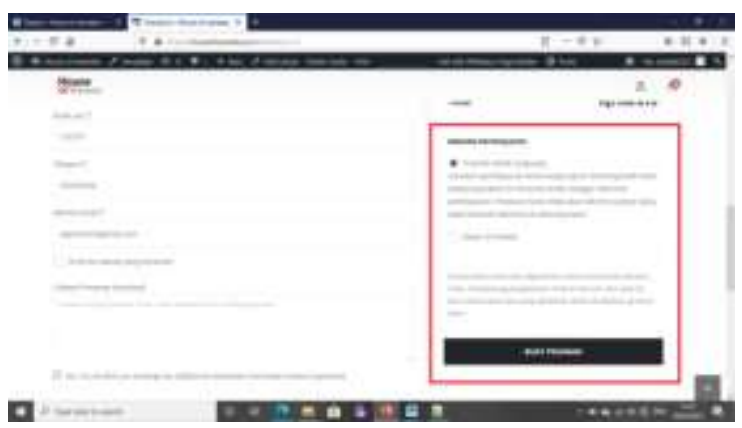

Gambar 9. Halaman Metode Pembayaran

\section{KESIMPULAN DAN SARAN}

Berdasarkan pembahasan mengenai pembuatan toko kosmetik berbasis web yang telah dibahas, penulis dapat memberikan kesimpulan diantaranya pelanggan bisa menerima informasi secara detail dalam hitungan detik, bukan lagi hari bahkan minggu. Adanya website sistem informasi penjualan kosmetik online ini, memberikan kemudahan bagi para pelanggan dalam memesan tanpa harus datang langsung ke toko. Aplikasi penjualan kosmetik online berbasis web lebih mudah dalam pengelolaan data.

Berdasarkan kesimpulan dari pembahasan penjelasan di atas, penulis memberikan beberapa saran sebagai alternative untuk menjadi seorang web programmer, selain itu juga dapat dijadikan masukkan yang berguna, dengan harapan agar dapat meningkatkan kualitas pengguna aplikasi website toko kosmetik online ini.

\section{DAFTAR PUSTAKA}

[1] Adzan Abdul Zabar, (2015). Keamanan HTTP dan HTTPS Berbasis Web Menggunakan Sistem Operasi Kali Linux Jurnal Ilmiah Komputer dan Informatika vol.4, No.2, Oktober 2015.

[2] Ajeng Haryati,(2020). Perancangan ECommerce Subang Make up Store Menggunakan Framework Codeigniter Proceding SENDIU .

[3] Ramadhan Rakhmat Sani,(2018). Perancangan E-commerce pada Produk Wingko Babat Pak Moel Berbasis Web Journal of Information System Vo. 03, No 02 Nopember 2018.

[4] Wahfiuddin Surya, (2020). Perancangan Aplikasi Mobile E-Commerce Perangkat Elektronik dengan Menggunakan Rest Api Berbasis Android IT Journal, Vol. 8 No. 2 Oktober 2020.

[5] Ajeng Haryati,(2020). Perancangan ECommerce Subang Make up Store Menggunakan Framework Codeigniter Proceding SENDIU .

[6] Ajeng Haryati,(2020). Perancangan ECommerce Subang Make up Store Menggunakan Framework Codeigniter Proceding SENDIU.

[7] Arjaka, S.(2010). Media Elektronik Berbasis Komputer Sebagai Media Dalam Proses Pembelajaran. Jurnal-online.um.ac.id.Malang.

[8] Hastanti, R. P., Purnama, B.E., \& Pacitan, I. U.W.-S.P. (2015). Sistem Penjualan Berbasis Web (E-Commerce) pada tata distro kab pacitan. Bianglala Infrmation, 3(2). https://doi.org/10.31294/bi.v3i2.581

[9] Numan Musyaffa,(2019). Pengambangan Aplikasi Sistem Informasi Penjualan Aksesoris Kendaraan Berbasis Web ECommerce Menggunakan Metode Waterfall Jurnal Khatulistiwa Informatika, Vol. VII, No.1 Juni 2019.

[10] Ginanjar Wiro Sasmito, (2017). Penerapan Metode Waterfall pada desain sistem informasi Geografis industri kabupaten tegal jurnal pengembangan IT (JPIT), Vol. 2, No. 1, Januari 2017. 